\title{
El mundo artesanal de dos ciudades del norte argentino. Salta y Jujuy, primera mitad del siglo XIX
}

Emma Teresita Raspi

Universidad Nacional de Jujuy

\begin{abstract}
El presente artículo intenta delinear la composición de los sectores artesanales de las ciudades de Salta y San Salvador de Jujuy durante la primera mitad del siglo XIX. El trabajo constituye una descripción de conjunto en la que se intenta delinear la heterogeneidad e identidad de estos sectores a partir de algunas variables como la estructura del sector por rubros, las modalidades de organización interna, la vigencia de la tradición colonial y la composición social y geográfica de esta porción de la población urbana. Ello enmarcado en un contexto de las luchas independentistas y civiles.
\end{abstract}

Los estudios sobre los sectores artesanales son relativamente escasos en la historiografía latinoamericana y generalmente forman parte de trabajos sobre los movimientos obreros. ${ }^{1}$ En Argentina, son aún pioneros los trabajos específicos sobre estos grupos sociales para el siglo XIX $;{ }^{2}$ a pesar de esta relativa ausencia en la historiografía regional, el análisis de los sectores artesanales resulta de suma importancia para comprender el entramado social urbano, así como los estudios de mercado.

El mundo artesanal urbano del norte argentino durante la primera mitad del Siglo XIX, acontecía en un escenario teñido por las turbulencias políticas y bélicas del período revolucionario independentista; tal era la experiencia de los residentes en las ciudades de Salta y San Salvador de Jujuy, quienes además comenzaron a probar ciertas transformaciones propias de la sociedad de mercado. En las primeras décadas de vida republicana, los límites entre pasado colonial y la modernidad fueron confusos, se confrontaron y fluyeron otorgando ciertas características propias a estas pequeñas sociedades urbanas del norte argentino. Ambas se distinguieron

1 Johnson Lyman: “Artesanos” en: Hoberman L. y Socolow S. (Comp): Ciudades y Sociedad en Latinoamérica colonial. Buenos Aires, 1992; Grez Tozo, Sergio: De la Regeneración del pueblo a la Huelga General. Génesis y evolución histórica del movimiento popular en Chile. (1810-1890). Santiago de Chile, 1997; Barragan Rossana: Espacio Urbano y dinámica étnica. La Paz en el Siglo XIX. La Paz, 1990; y Sowell David, The early Colombian Labor Movement. Artisans and Politics in Bogotá, 1832-1919. Philadelphia, 1992

2 Sábato, Hilda y Romero, Luis Alberto: "Artesanos, oficiales, operarios: Trabajo calificado en Buenos Aires, 1854-1887”. En: Armus, Diego (Comp): Mundo Urbano y Cultura Popular. Buenos Aires, 1990; y Bascary, Ana María: Los Artesanos de San Miguel de Tucumán a fines del Período Colonial. MS. Universidad de Sevilla. 
por sus nutridos movimientos comerciales, ya que se ubicaban en los caminos que conectaban a las pampas rioplatenses con los mercados de las minas de plata altoperuanos. El comercio de ganado en particular, había contribuido a otorgarles una destacable fisonomía mercantil, pues los centros de reunión para la compra-venta de ganado o los lugares de invernada de las mulas se ubicaban en puntos muy cercanos a estos espacios urbanos. La distancia que separa a ambas ciudades es relativamente pequeña, aproximadamente ciento veinte kilómetros y a principios de siglo el viaje entre una y otra empleaba dos jornadas "yendo a caballo". El viajero que llegaba del norte podía obviar su estadía en Salta pero el paso por Jujuy era necesario pues tenía la especial característica de ser el punto donde comenzaba el camino carretero que conducía a Buenos Aires.

En los albores del siglo XIX ambas fueron afectadas profundamente por los conflictos ocasionados por la independencia y las posteriores luchas civiles, puesto que constituyeron puntos de avanzada durante las guerras y a menudo campos de batalla. En tal sentido, el comercio en ambas se vio seriamente afectado por contribuciones, levas de población o "éxodos" como en el caso de Jujuy. El mercado de ganado en especial fue seriamente perjudicado por la prohibición de las ventas al enemigo y por la obligación de entrega al ejército en forma de "contribuciones de guerra" o "empréstitos". Tales circunstancias modificaron relativamente la función de estas ciudades y así lo señaló el ciudadano Joaquín Carrillo en Jujuy, con su recién estrenado sentimiento patriótico: "La conclusión de la guerra del Perú ha cambiado la posición de esta provincia. Después de haber sido por el largo espacio de quince años el cordón sanitario contra la maligna influencia de la tiranía metropolitana, empieza hoy a formar la frontera de las provincias argentinas, y el punto de contacto de ésta con la nueva República de Bolivia...". ${ }^{3}$

En este contexto el análisis del sector artesanal presenta un especial interés para la comprensión de las sociedades urbanas, por sus características socioeconómicas y su rol de proveedores de los mercados locales y regionales; ofrecen así una compleja gama de pautas de la vida económica, debido a la diversidad de oficios que cubrían las demandas de los mercados locales. Asimismo, el estudio de la producción artesanal presenta una realidad bastante compleja y fragmentaria, lo cual se debe por un lado, a la escasez de las fuentes en los espacios que estudiamos y, por otro, a la diver-

3 Carrillo, Joaquín: Descripción de la Provincia de Jujuy. Informes de objetos y datos que presenta el comisionado provincial, el Senador Nacional. Don Eugenio Tello a la exposición universal de 1889 en París. San Salvador de Jujuy, 1988. 
sidad y cantidad de actores que conformaban el sector; éstos diferían en sus orígenes, composición étnica u oficios, lo que implicaba prácticas y formas de organización del trabajo diferente. ${ }^{4}$

\section{Composición de los rubros artesanales}

Los sectores artesanales a pesar de su innegable importancia en el abasto urbano, constituían una reducida parte de la sociedad que fue cre- $^{5}$ ciendo según los ritmos que impuso el lento aumento demográfico de ambas ciudades, durante los cuales la composición de la población artesanal no varió significativamente. Los rubros que alcanzaron mayor desarrollo fueron los correspondientes a la construcción y mobiliario, seguidos por lo que se dedicaban a la producción de cueros; los primeros crecieron alentados por el crecimiento urbano y los últimos por la demanda de carácter interregional del producto.

Quienes se dedicaban a la elaboración de los insumos necesarios para la construcción, desarrollaban sus actividades en los márgenes del espacio urbano, en establecimientos denominados de "material cocido", donde se producían los típicos ladrillos y tejas, elaborados con materiales provenientes de localidades muy cercanas o en el mejor de los casos de los alrededores. ${ }^{6}$ Dentro del ámbito de la construcción, los oficios más numerosos eran los ejercidos por carpinteros y albañiles, los últimos trabajaban bajo las órdenes del maestro del oficio o de un arquitecto, en caso de edificios públicos. También los escasos pintores eran empleados por las instituciones públicas y algunos particulares, especialmente cuando se acercaban las fechas de las fiestas importantes, durante las cuales era signo de decoro tener presentables las fachadas de los edificios.

Los numerosos fabricantes de artículos de cuero fueron los que expandieron con mayor éxito sus actividades, debido a la importante

4 Las investigaciones que llevamos a cabo sobre este tema son pioneras en los espacios y tiempos que estudiamos.

5 La ciudad de Jujuy contaba con 1.533 habitantes hacia 1823, de los cuales sólo 84 individuos aparecen en los padrones censales con oficios artesanales. Hacia 1851, de los 2.309 habitantes sólo 137 eran artesanos. Las estimaciones sólo se pueden efectuar para la ciudad de Jujuy, donde contamos con los siguientes padrones de población, que se encuentran en el Archivo Histórico de la Provincia de Jujuy (en adelante AHPJ): Padrón del año 1823, en la Caja de Gobierno (CG) de 1823 N. ${ }^{\circ}$ 1; el Padrón de 1851 en CG año 1851 N. ${ }^{\circ}$ 2. En el caso de la ciudad de Salta tal estudio es imposible puesto que carece de tales fuentes censales.

6 Carrillo, Joaquín: Descripción..., págs. 52 y 53 
demanda generada por las diversas utilidades de este artículo, el establecimiento de varias curtiembres dentro del cono urbano y la calidad de las confecciones. Los viajeros apreciaban de manera singular la labor de los artesanos del cuero, así lo manifiestan las expresiones del viajante europeo Erick Von Rosen: "Los objetos, que enseguida describo y que pertenecen al equipo del gaucho, son verdaderas obras maestras de artesanía casera argentina. El lazo, la boleadora y la taba, todo menos el cuchillo, muy bien podrían haber pertenecido a algún estanciero de tiempos pasados".?

Los cueros eran procesados en las curtiembres, donde además se cortaban las suelas para los calzados y vaquetas. ${ }^{8}$ Algunos detalles sobre tal proceso nos lo brinda en un informe el Senador Nacional por Jujuy, Eugenio Tello: "Los materiales empleados son la cal de fácil fabricación, para desengrasar y aflojar el pelo, el cebil para curtir. Hai en abundancia de este vegetal formado de los bosques de mucha estención en los valles. El laboreo es lento i la suela se queda lista solo seis meses después de comenzado el tratamiento del cuero". ${ }^{9}$ En tales menesteres se empleaban cueros de los animales que abundaban en la región, como los del ganado vacuno, de diversos tipos: becerros, cordobanes y nonatos, aunque también se empleaban los de perros, cabras y cerdos del monte. ${ }^{10}$

Las suelas de las curtiembres eran utilizadas por los zapateros para la confección de varios tipos de calzado y, con el tiempo, el difundido uso de las botas llevó a una especialización del gremio en la confección de este artículo. El trabajo del cuero empleaba a diversos trabajadores especializados en los utensilios indispensables para las cabalgaduras y otros usos del jinete. Los lomilleros ${ }^{11} \mathrm{y}$ trenzadores se dedicaban principalmente a confeccionar tientos, cordeles, cinturones y lazos ${ }^{12}$ también eran diestros en la confección de las típicas boledoras, ${ }^{13}$ útiles para atrapar ganado. Los talabarteros eran diestros en los indispensables "guardamontes", piezas de cuero crudo que

7 Von Rosen, Eric: Un mundo que se va. Universidad Nacional de Jujuy, 1990, pág.33.

8 Son cueros de ternera curtidos y adobados, es decir preparados con sustancias que los dejan aptos para ser trabajados para diversos fines.

9 El cebil es un árbol que abundaba en toda la región del actual noroeste argentino.

10 Carrillo, Joaquín: Descripción..., pág. 42

11 Trabajador del cuero, quien se especializa en efectuar costuras con dos puntadas cruzadas, así elabora las piezas del recado de montar, y las que se ponen a las caballerías de carga.

12 Carrillo, Joaquín: Descripción..., pág. 43

13 Von Rosen, Eric: Un mundo..., pág 44. El autor describe el procedimiento para fabricar una boleadora: “... se corta por el medio una tira de cuero crudo de unos dos metros de largo, dejando en ambos extremos un pedazo de $20 \mathrm{~cm}$ sin partir. Esta tira se tuerce luego...Las bolas casi redondas de piedra, no muy pesadas y cosidas en cuero, se fijan después una en cada extremo de dicha tira. En el centro de ésta se ata otra tira de un metro de largo, hecha de la misma manera..." 
cuelgan de la parte delantera de la montura y sirven para defender las piernas del jinete de la espinosa vegetación de los montes del norte argentino.

Algunas profesiones fueron de gran demanda en tiempos de guerra, como el menudo grupo de los herreros, armeros y fundidores, los últimos desaparecieron con el cese de los conflictos, es decir que migraron o se dedicaron a oficios afines. Todos ellos se abocaban a la producción y reparación de lanzas, sables, herraduras, piezas de fusil, etc. En tiempos de paz, el trabajo de los herreros y plateros era requerido preferentemente para la composición de variados artículos del jinete, como estribos, espuelas y sobre todo: el cuchillo, elemento tan preciado que Erick Von Rosen exclamaba “...el cuchillo es la prenda más cara para el gaucho, y creo que muchas veces prefiere perder la china[su mujer] y no el cuchillo, especialmente si este lleva hoja de buen acero y mango de plata...". ${ }^{14}$

El gremio de plateros gozaba de notable reputación entre las élites, pues empleaban gran maestría en el revestimiento de los utensilios y adornos que los diferenciaba del resto de la sociedad. En Salta, este gremio destacó especialmente en la confección de diversos artículos religiosos.

El nutrido contingente de sastres y costureras tuvo un fuerte aliciente durante las décadas de conflictos bélicos, debido a la demanda de uniformes para las milicias. El trabajo del sastre gozaba de mayor consideración que el de las mujeres, ya que la tradición gremial que sólo incluía a los hombres los acreditaba al respecto, es por ello que a los primeros se les encargaba la confección de uniformes para los oficiales de alto rango del ejército, mientras que las costureras elaboraban las prendas de los soldados. Es así como las remuneraciones fueron también diferentes, mientras a ellos se les pagaba por la calidad a ellas por la cantidad.

Otra profesión que gozaba de gran demanda era la del sombrerero, la mayoría de estos artesanos provenía de las ciudades bolivianas. Los sombreros podían ser de distintas calidades y precios según el material de la confección, los más cotizados eran los de cuero de vicuña, animal de la puna y los más frecuentes eran los preferidos por: "La gente de la campaña es la que más usa de los de lana; sirviéndose la generalidad del sombrero europeo". ${ }^{15}$ Otros rubros artesanales que lograron cierto desarrollo fueron las lozerías y jabonerías, cuyas instalaciones eran mayores que las de los talleres y se ubicaban en las márgenes del radio urbano.

14 Ibídem, pág. 42.

15 Carrillo, Joaquín: Descripción..., pág. 59. El autor señala en su informe que los sombreros de vicuña costaban 10 pesos cada uno y los de lana 2 pesos. 


$$
\text { CuAdro N. }{ }^{\circ} 1
$$

EVOLUCIÓN DE LOS RUBROS ARTESANALES.

SAN SALVADOR DE JUJUY. 1810-1850

\begin{tabular}{lrr} 
& 1823 & 1851 \\
\hline Sastres & 18 & 15 \\
Zapateros & 26 & 25 \\
Carpinteros & 8 & 28 \\
Herreros & 9 & 11 \\
Plateros & 4 & 6 \\
Albañiles & 8 & 9 \\
Lomilleros & & 13 \\
Sombrereros & 1 & 16 \\
Talabarteros & & 4 \\
Trenzadores & 1 & \\
Armeros & 3 & 1 \\
Cigarreros & & \\
Boteros & & 5 \\
Otros & 5 &
\end{tabular}

Fuentes: AHPJ, CG 1823 n. ${ }^{\circ} 1$ y CG 1851 n. ${ }^{\circ} 2$.

Hacia la segunda mitad del siglo la composición de los rubros artesanales se mantuvo, aunque se comenzaron a diversificar las ocupaciones y aparecieron algunas especialidades nuevas como toneleros y tipógrafos.

Peter Burke ${ }^{16}$ señala que los gremios artesanales revisten ciertas características que los hacen peculiares, ya que se trata de un grupo social que conformarían una "subcultura " de hombres sin mujeres. La afirmación de Burke, resulta aplicable en la esfera del trabajo de los talleres; sin embargo, las mujeres no estaban ausentes de estos rubros, puesto que con frecuencia se encargaban de las finanzas del taller y del cobro de los trabajos realizados por los hombres. Por otra parte, el trabajo femenino se extendió entre rubros como el textil y en el campo de la elaboración de velas y ollas de arcilla. Estas actividades distaban de ser consideradas oficios en el sentido tradicional, puesto que se elaboraban en el ámbito del hogar, sin la necesidad del proceso de aprendizaje y especialización del artesano; la

16 Burke, Peter: La cultura popular en la Europa Moderna. Madrid, 1996. 


\section{GRÁFICO N. ${ }^{\circ} 1$}

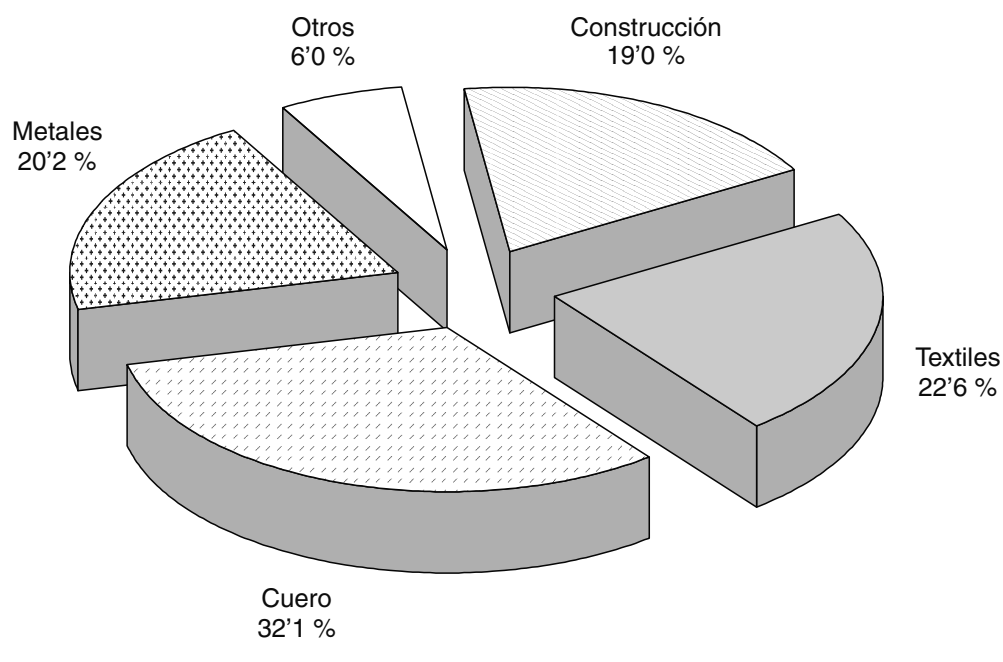

Fuente: AHPJ, CG 1823 n. ${ }^{\circ} 1$.

\section{GRÁFICO N. ${ }^{\circ} 2$}

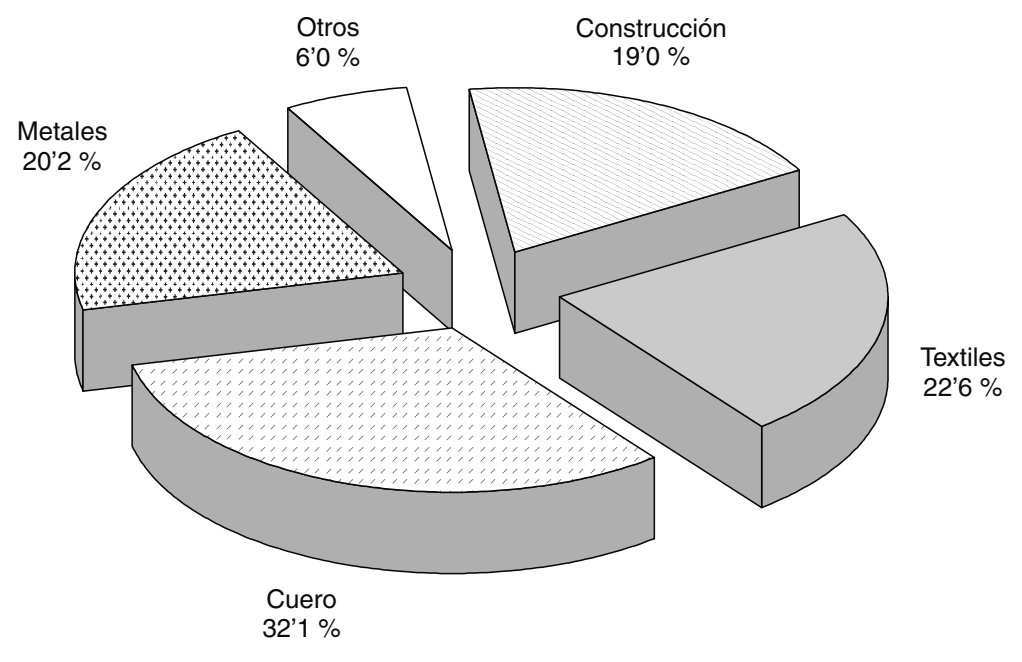

Fuente: AHPJ, CG 1851 n. ${ }^{\circ} 2$. 
comercialización se efectuaba mayormente en las calles o en algunas pulperías, como medio de complementar ingresos. Las fuentes legislativas indican que se trataba de cuenta-propistas muy pobres, por lo que comúnmente estuvieron exentas de las imposiciones fiscales.

\section{Algunas consideraciones sobre la heterogeneidad del sector}

Las ciudades de Salta y Jujuy se distinguieron por sus nutridos movimientos comerciales ya que se ubicaban en los caminos que conectaban a las provincias del sur con los mercados altoperuanos. Desde la etapa colonial, ambas constituyeron importantes puntos donde los viajeros podían hacer un alto y proveerse de los insumos necesarios para continuar su camino; por esta razón las perspectivas de desarrollo para algunos oficios artesanales eran posibles. Durante las primeras décadas del siglo XIX, el flujo migratorio de artesanos fue tan importante dentro del sector, que el grupo de nativos de la ciudad de Jujuy, por ejemplo, constituía una minoría ${ }^{17}$ frente al contingente que migraba desde las ciudades del interior argentino, como Tucumán, Córdoba y Buenos Aires. Si bien los conflictos bélicos desatados en estos territorios, actuaron como un factor de expulsión de población, en el caso de los artesanos, ocasionalmente, cumplieron un papel inverso, pues algunas compañías se trasladaron junto a las tropas del ejército, para el trabajo en la confección y reparación del armamento. ${ }^{18}$ Entre los países expulsores de población artesanal, Bolivia aportó el mayor volumen durante todo el período; los artesanos bolivianos se dedicaron fundamentalmente a los oficios de sombrerero y zapatero. Los migrantes de otros países limítrofes fueron escasos y sólo eventualmente se instalaba algún europeo.

El contingente de personas que trabajaban en los diversos talleres artesanales, además de tener orígenes geográficos diversos, provenía de condiciones sociales también diferentes: desde esclavos libertos ${ }^{19}$ hasta los maestros religiosos que dirigían la construcción de templos. ${ }^{20}$ En este sen-

17 Para este tipo de análisis se tomaron solamente los datos recogidos de los padrones completos de la ciudad de Jujuy de 1823 y 1851.

18 AHS. CG 1811 N..$^{\circ}$ 2. Como fue el caso de la compañía de carpinteros que se envió a Jujuy desde Salta para el trabajo de las "cureñas de los cañones".

19 AHPJ Actas Capitulares de San Salvador de Jujuy, tomo 1, del 31de julio de 1813.

20 Chiericotti, Olga: La Catedral de Salta. Salta, 1999. La autora señala que la construcción de la iglesia catedral estuvo a cargo de los maestros constructores dirigentes don Diego Acevedo, don Juan Costilla y don Nicolás Carrizo. 
tido, el factor étnico, que impregnaba todas las relaciones entre los grupos humanos, también fue un elemento presente en la composición y consideración del sector; hacia 1820 el contingente de los artesanos de Jujuy estaba compuesto por un $29 \%$ de personas pertenecientes a las castas, distribuidas entre negros, pardos, morenos y mulatos; la mayoría de ellos se desempeñaron en oficios tan humildes como los de zapatero y albañil.

$$
\text { CUADRO N. }{ }^{\circ} 2
$$

POBLACIÓN ARTESANAL DE S.S. DE JUJUY 1823 Y 1851

\begin{tabular}{lcc} 
Orígen & \multicolumn{1}{c}{1823} & 1851 \\
\hline Nativos & $31-37,34 \%$ & $54-39,41 \%$ \\
Foráneos & $41-49,39 \%$ & $69-50,36 \%$ \\
No se sabe & $11-13,25 \%$ & $14-10,21 \%$ \\
Total & $83-100 \%$ & $137-100 \%$
\end{tabular}

Fuentes: AHPJ, CG 1823 n. ${ }^{\circ} 1$ y CG 1851 n. ${ }^{\circ} 2$.

$$
\text { CUADRO N. }{ }^{\circ} 3
$$

ORÍGENES DE LOS MIGRANTES ARTESANOS. SAN SALVADOR DE JUJUY 1823-1851

\begin{tabular}{lrr} 
& 1823 & 1851 \\
\hline Chile & 2 & 0 \\
Perú & 4 & 0 \\
Otros Países & 1 & 2 \\
Salta & 9 & 29 \\
Tucumán & 2 & 17 \\
Catamarca & 0 & 1 \\
Pcias del Sur & 5 & 5 \\
Jujuy & 31 & 54 \\
Interior Jujuy & 1 & 2 \\
No se sabe & 11 & 14 \\
Bolivia & 17 & 13
\end{tabular}

Fuentes: AHPJ, CG 1823 n. ${ }^{\circ} 1$ y CG 1851 n. ${ }^{\circ} 2$. 


\section{Algunas miradas sociales sobre el sector}

En el colectivo social, entonces, el ejercicio de las artes mecánicas no era considerado tan prestigioso como otros, a pesar de los intentos de reivindicación realizados por la corona española a fines del siglo XVIII. ${ }^{21}$ Así es que, durante la primera mitad del siglo XIX, ningún artesano guardaba relaciones parentales directas con las familias de las elites. Por otra parte se trataba de un grupo social considerado extremadamente pobre y débil, por lo tanto, merecedor de la protección de las autoridades municipales, quienes los veían como: “... una de las clases más necesitadas en la sociedad y que libran su suerte a su trabajo personal e industria que poco les produce”, ${ }^{22}$ por consiguiente, decidieron omitir cobrarles el impuesto de patentes por abrir sus talleres. Si bien las autoridades locales no observaron una conducta contraproducente hacia el sector, tampoco fomentaron su desarrollo. En este sentido la legislación emitida sólo aludió a ciertas pautas de organización interna, referidas al control del trabajo de los oficiales y trabajadores por parte de los maestros. ${ }^{23}$

La localización espacial de los diversos sectores sociales actuó como factor que permitía el desarrollo de ciertas características por cuanto diferenciaba y ubicaba a cada uno dentro del entramado social. Así es que los grupos artesanales tendieron a agruparse de manera relativamente compacta en zonas o barrios marginales ${ }^{24}$ en la ciudad de Salta, la concentra-

21 “... que sólo la ociosidad, la vagancia y el delito causan la vileza; y que ningún oficio deja de ser bueno, como que no ofende a las costumbres ni al Estado, antes bien fomenta a uno y otro; sin que por esto se les hubiese querido elevar al último grado de honor. O igualarlos a las ocupaciones o empleos superiores, ni constituir, aún entre los mismos oficios mecánicos, una igualdad que sería quimérica por la diversidad de objetos y utilidades...”. Extracto de la Cédula Real del 4 de septiembre de 1803 en: Escriche, Joaquín: Diccionario Razonado de Legislación y Jurisprudencia. México, 1912.

22 AHS. Registro Oficial de Salta, número 8. Expediente del 3 de agosto de 1832. “...Habiendo en algún modo cesado los motivos urgentísimos que precisaron al Gobierno a adaptar la medida de gravar a los artesanos con el derecho de $2 \$$ o patente cada cuatrimestre. Teniendo en consideración que siempre les es gravoso, al paso que es una de las clases más necesitadas en la sociedad y que libran su suerte a su trabajo personal e industria que poco les produce. Ha Acordado y Decreta: Artículo único: Desde la fecha en adelante, todos los artesanos comprendidos en el artículo 14 del decreto de 3 de marzo, quedan libres de pagar el derecho de patente de $2 \$$ que previene dicho artículo..."

23 Tello, Eugenio: Compilación de Leyes y Decretos de la Provincia de Jujuy. Desde el año 1835 hasta el de 1884. San Salvador de Jujuy, sin año de edición. Tomo II. Registro Oficial del 3 de junio de 1859.

24 Caretta de Gauffin, Gabriela y Marchionni, Marcelo: "Estructura urbana de Salta a fines del período Colonial”, Revista Andes, 7, CEPHIA, Universidad Nacional de Salta, 1995/96. 
ción de talleres le dio su nombre a la calle de "las Artes". ${ }^{25}$ Los locales de dimensiones considerables como curtiembres y fábricas de ladrillos debieron ubicarse en puntos extremos del espacio urbano, a orillas de los ríos cercanos. Un fenómeno distinto ocurría en Jujuy, ciudad menos populosa, donde la dispersión de los artesanos fue más evidente, aunque varios cuartos y talleres se instalaron en las barrancas de los ríos que rodeaban y limitaban la ciudad. ${ }^{26}$

Acentuando nuestra mirada dentro del sector, observamos que, de acuerdo a la diversidad de oficios y utilidades desplegadas por los artesanos, se abría una serie de consideraciones jerárquicas que variaban de acuerdo con el rubro y el título profesional. Se observó que en Jujuy los maestros armeros y herreros alcanzaron prestigio en el ejército, por lo que se les encargaba la dirección de las maestranzas y en Salta estuvieron a cargo de maestros plateros. ${ }^{27}$ Fueron estos últimos quienes probablemente gozaron de mayor estima entre los miembros de la elite salteña, al revestir con plata los utensilios que le otorgaban prestigio social; también su labor era requerida por el clero en la confección de diversos elementos considerados de uso sagrado. Las profesiones más humildes fueron precisamente las más numerosas, como las de zapateros y albañiles; entre ellos se registró la mayor cantidad de personas de color y esclavos libertos. Contaban con los salarios más bajos y era el sector en que se registró el menor número de propietarios.

\section{Vigencia de la tradición española en la estructura gremial}

La antigua legislación colonial establecía que, para ser admitido en un gremio, era necesario haber trabajado en el oficio como aprendiz y mancebo cierto número de años, rendir un examen al cabo de ellos, presentando una obra maestra, llamada pieza de examen, y pagar cierta cantidad de dinero. El que no se sujetase a estas formalidades no podía ejercer su industria por más que sobresaliese en ella. Con el paso de la Colonia a la

25 DIGESTO MUNICIPAL de la ciudad de Salta. (sin datos de edición) en AHS.

26 Gil Montero, Raquel: La Población de Jujuy entre 1779 y 1869. Tesis de Licenciatura. Facultad de Filosofía y Humanidades. Universidad Nacional de Córdoba. 1993, pág 74. La autora señala que las tiendas y viviendas de artesanos se repartían en general por toda la ciudad y en particular en las manzanas ubicadas en el extremo noreste.

27 AHS, CG 1822/23. En las listas de pago de las maestranzas del ejército de Salta, figuran los nombres de los maestros plateros encargados de las mismas: Fresco y Sebastián Acosta. 
Independencia la legislación se flexibilizó, ${ }^{28}$ pero las modalidades de organización de la estructura artesanal continuaron vigentes durante la primera mitad del siglo XIX, por ello encontramos a maestros, oficiales y aprendices participando de los procesos de trabajo.

El primer paso que se debía dar para formar parte del sector artesanal, consistía en ser aceptado como aprendiz de un oficio y ponerse bajo la tutela de un maestro dispuesto a enseñar. Los casos estudiados muestran que, generalmente, los aprendices eran los mismos hijos del maestro o de los oficiales que continuaban con la profesión de sus padres..$^{29}$ Aunque también analizamos casos en que los jóvenes seguían profesiones diferentes a las de sus progenitores, ${ }^{30}$ especialmente cuando se trataba de oficios muy humildes y con pocas perspectivas de progreso económico. De acuerdo a los testamentos, se infiere que los términos del proceso de aprendizaje se establecían según una contrata estipulada entre el maestro y el padre, o responsable del aprendiz, quien generalmente era menor de edad. El postulante vivía en la casa taller del maestro, ${ }^{31}$ sin percibir salario alguno, pero bajo su manutención y a cambio de su trabajo personal, durante el tiempo que duraba el proceso de aprendizaje. ${ }^{32}$ La posibilidad de aprender y trabajar en el taller significaba, para el aprendiz, una primera forma de emancipación familiar, pues ya no dependía de la autoridad paterna; ello no impli-

28 Escriche, Joaquín: Diccionario Razonado... En las reales órdenes del 1.º de marzo de 1798 se dispuso que "todas y cualesquiera personas pudieran trabajar en sus oficios y profesiones, sin otros requisitos que el de hacer constar su pericia, aunque les faltasen los de aprendizaje, oficialía, domicilio y demás que prescribían las ordenanzas gremiales". El 29 de junio de 1815 se ordenaba que "si se restablecían las ordenanzas gremiales, se mandaba al mismo tiempo examinarlas y suprimir todo lo que pudiera causar monopolio por los del gremio, lo que fuese perjudicial al progreso de las artes y lo que impidiese la justa libertad que todos tenían de ejercer su industria, acreditando poseer los conocimientos de ella por las obras que presentasen".

29 AHS, Protocolos Notariales(PN), Escribano Arteaga, carpeta núm. 30, protocolo núm. 316, expediente 78. Testamento del maestro carpintero Acunia, quien declara se eduque a su hijo en el mismo arte.

AHPJ, CG 1851 núm. 2. Los hermanos Olmos eran todos talabarteros. Para citar como ejemplos de esta costumbre.

30 AHPJ, CG 1823 núm. 1 Tal era el caso del sastre de apellido Sueldo que tenía dos hijos zapateros.

AHPJ, CG 1851 núm. 2. El platero Benítez tenía dos hermanos herreros y eran hijos del sastre Nicolás Benitez. Ellos fueron dos de los numerosos casos que figuran en los padrones.

31 AHPJ, CG 1851 núm. 2. Esta situación se puede inferir a partir de lo observado en los padrones de la ciudad de Jujuy de 1851, donde se registraron cuatro casos (un sastre y tres herreros) donde se explicita que en casa del maestro artesano convivían sus aprendices.

32 AHS, PN. Escribano Arteaga, carpeta 30, protocolo 316, expediente 78. "Advirtiéndose que por pretexto alguno, ni su madre que por que yo lo he criado a mi costa y podrá sacarlo del poder de Argüello, ni mis albaceas, a no ser que falte con los alimentos, el vestuario o se le advierta que le enseñe vicios, probado que sea se recogerán y darán a otro maestro del mismo arte..." 
caba un desentendimiento total de la familia ya que, al finalizar la etapa de aprendizaje, el joven pasaba a percibir un salario como oficial, colaborando así con la economía familiar. ${ }^{33}$

En un grado superior, pero dependiente aún de las órdenes de los maestros, se encontraban los oficiales, quienes constituían el contingente de mano de obra calificada, debido a los conocimientos que habían adquirido sobre el oficio durante sus años de aprendices. Los oficiales eran empleados a través de contratos temporales que, durante algunas décadas, se hicieron bajo la forma de "conchavos" ${ }^{34} \mathrm{El}$ uso de este término en el contrato de oficiales se presta a confusión puesto que también era utilizado para emplear a la mano de obra no calificada, como aquellos "vagos y mal entretenidos, que no tenían profesión ni arte", a quienes la legislación salteña de 1832 intentaba trasladar al campo productivo. ${ }^{35}$ Por el momento carecemos de elementos suficientes para saber si las leyes de conchavo buscaban satisfacer una demanda insatisfecha de mano de obra del sector, o sólo constituían un medio eficaz para impedir la vagancia. También nos preguntamos hasta qué punto tales disposiciones no actuaron como herramientas desestructurantes de la organización interna y tradicional de los gremios, al incorporar mano de obra no calificada.

Como autoridad máxima dentro del taller, los maestros regulaban el contrato y desempeño de los oficiales; por lo tanto, la acreditación de otro maestro era garantía suficiente para contratar un trabajador calificado. ${ }^{36} \mathrm{La}$ condición de trasmitir los saberes propios del oficio les otorgaba una serie de derechos y obligaciones sobre sus aprendices, factibles de ser observadas en el testamento del maestro lomillero, José Acuña, quien decía así: “... mando que tan luego Dios sea servido llevarme, sea entregado mi hijo José Manuel, al maestro Mariano Argüello, quien cita encargado por mi de su educación y cuidado, se les entregara todas mis herramientas para

33 AHS, PN. Escribano Arteaga, carpeta 30, protocolo 316, expediente 78. “....será entregado por contrata y tiempo limitado para que con su trabajo personal pueda aliviar a su madre, de todo lo que cuidarán mis albaceas...”.

34 AHS, Registro Oficial de Salta, núm. 8 del 1 de agosto de 1832. “...Art.5 Los Maestros de cualesquiera arte u oficio deberán mensualmente sacar de la Policía una papeleta para cada uno de los oficiales que tengan en su taller. Art.7 Los Maestros artesanos que tuviesen oficiales en su taller y los patrones que conchaven peones, así que falten al servicio dos días, deberán avisarlo a la policía para su aprensión...”

35 Ibídem. “... Todo individuo de la Provincia que no tenga profesión, arte u oficio de que pueda ganar la vida, será obligado a conchavarse y solicitar patrones que lo destinen a algún género de trabajo, a los 8 días de la publicación de este decreto..."

36 Tello, Eugenio: Compilación de Leyes y Decretos... Registro Oficial del 3 de Junio de 1859. T. II. 
que trabaje con ellas y le enseñe al dicho mi hijo el oficio: "Advirtiéndose que por pretexto alguno, ni su madre que por que yo lo he criado a mi costa y podrá sacarlo del poder de Argüello, ni mis albaceas, a no ser que falte con los alimentos, el vestuario o se le advierta que le enseñe vicios, probado que sea se recogerán y darán a otro maestro del mismo arte". ${ }^{37}$

Las disposiciones emanadas en este testamento ponen de manifiesto la fuerza con que actuaban los lazos corporativos sobre los individuales, puesto que la indiscutible autoridad paterna sólo reconocía como un equivalente a la figura de otro maestro; ni siquiera la madre u otra autoridad, tenían el derecho de reclamar la custodia del aprendiz. Nótese también, el aprecio y la necesidad de transmitir el estilo de vida artesanal latente en el padre, quien emplea todos los medios necesarios para asegurar y perpetuar el oficio en su hijo. Los maestros generalmente se beneficiaban, como en este caso, con las herramientas y la mano de obra del aprendiz, sin embargo, estaba entre sus obligaciones mantenerlos, trasmitirles el arte del oficio y un estilo de vida digno y honesto. Estas prácticas, aparentemente comunes, se llevaban a cabo según el acuerdo al que arribaban las partes, sin que mediara una regulación municipal al respecto. Tanto el escribano como los albaceas actuaban como autoridades habilitadas para garantizar el cumplimiento de los términos del contrato.

Dentro del sector se mantuvo latente la difundida tendencia entre maestros, oficiales y aprendices de convivir en el taller del maestro, ${ }^{38}$ es por ello que la casa-taller era el ámbito de convergencia de la vida doméstica familiar, la vida laboral y de educación profesional del núcleo de artesanos. ${ }^{39}$

Además de los saberes propios del oficio, algunos maestros eran conscientes del valor de la lectoescritura como condición de ascenso social en el ámbito urbano; es por ello que este tipo de instrucción se difundió sólo entre quienes gozaban de este escalafón jerárquico; ${ }^{40}$ por el contrario, la mayoría de los integrantes del sector artesanal era analfabeta. La posibilidad de leer y escribir, entonces, permitía escalar o defender posiciones, así

37 AHS, PN Escribano Arteaga, carpeta 30, protocolo 316, expediente 78. Testamento del maestro carpintero del 11 de Junio de 1843.

38 AHPJ, CG 1851 núm. 2. El padrón indica que el maestro carpintero Solórzano, de Tucumán, vivía con sus dos oficiales Felipe Medina y Rosa Carrizo.

39 AHS, PN. Escribano Arteaga, protocolo 316, carpeta 30, expediente 78.

40 Manejan estas habilidades maestros como: el maestro Bustos, que firma las boletas de cobro del salario a nombre de otros artesanos que no saben hacerlo. AHPJ, CG. 1811 núm. 1. El maestro Acunia firma él mismo su testamento. AHS Escribano Arteaga, carpeta 30, protocolo 316, expediente 78. El herrero de apellido Gonzalez era apoderado del maestro Juan Rodríguez: AHS. PN. Escribano Molina, protocolo 266, carpeta 25, expediente 32. 
algunos fueron apoderados o testigos de sus pares en diversos litigios. ${ }^{41} \mathrm{La}$ figura de los maestros cobraba mayor importancia aún, cuando la rentabilidad de sus negocios les permitía hacer pequeños préstamos a quienes resultaban menos afortunados en sus actividades laborales. ${ }^{42}$

Otras actividades a cargo de los maestros eran las referentes al ámbito comercial, puesto que debían proveerse de los insumos necesarios en las maestranzas y talleres, vender sus productos o bien, conseguir contratos laborales; por lo cual establecieron fuertes contactos con los tenderos y pulperos de la ciudad. ${ }^{43}$

\section{Los talleres}

Las formas de organización del trabajo artesanal variaba de acuerdo con la demanda de los productos y los capitales invertidos en los establecimientos. La producción en talleres de carácter doméstico era una de las formas predominantes ${ }^{44}$ La tendencia a vivir en el hogar del maestro, se acentuaba cuando la compañía o núcleo artesanal migraba de una región a otra. ${ }^{45}$ En estos casos, el grupo familiar de cada uno de los miembros del grupo solía estar ausente, aunque se registraron casos donde sólo la familia del maestro compartía el hogar con el grupo de oficiales. ${ }^{46}$ Otros personajes que solían vivir en los talleres domésticos fueron aquellos que se empleaban en calidad de sirvientes; tales trabajadores podían desempeñarse como personal doméstico o bien como ayudante del taller; si bien estas prácticas se hicieron más frecuentes a lo largo del siglo XIX, no solían ser símbolo de

41 AHS, CG 1811. El 9 de agosto de 1811 El Herrero Bustos firmó a nombre de Jorge Olivera que no sabía hacerlo.

42 AHS, PN. Escribano Arteaga, protocolo 316, carpeta 30, expediente 78. o bien, AHS, PN. Escribano Niño, protocolo 337, carpeta 34, expediente 263.

43 AHS, CG 1825 núm. 4. En las listas de pagos de la ciudad de Salta del 17 de septiembre de 1825 , el maestro pintor "Eugenio" recibe 22 pesos por los materiales que consiguió para la Sala de Representantes.

AHPJ, CG 1811 núm. 1. Aquí figuran diversos comprobantes de las compras de hierro que hizo el maestro carpintero Díaz.

44 De acuerdo a la información que se observa en los padrones de 1823, 1834, 1843 y 1851.

45 AHPJ, CG 1851 núm. 2. El maestro lomillero Del Castillo, salteño, vivía con su familia y cinco oficiales, todos eran salteños y solteros.

46 AHPJ, CG 1851 núm. 2. El maestro carpintero Solórzano vive con sus dos oficiales Medina y Carrizo.- Por su parte, el maestro Ávila, sombrerero colombiano, vivía con su mujer y cuatro hijos, los mayores también sombrereros y dos sombrereros más, que probablemente eran sus oficiales o ayudantes. En AHPJ, CG 1843 núm. 2 
status, más bien pueden interpretarse como un indicador de la necesidad imperiosa de aumentar la productividad del taller.

El pago por el trabajo de maestros y oficiales en los talleres variaban de acuerdo al tipo de trabajo demandado; la confección de artículos significaba mejores retribuciones, que variaban según quién aportara los materiales. ${ }^{47} \mathrm{El}$ trabajo de recomponer piezas era considerado de menor valor, dependiendo del tipo de conocimiento requerido. ${ }^{48}$ Las formas de pago en los talleres se fijaban según el acuerdo al que arribaban el maestro y el oficial; al respecto las autoridades locales prohibían la difundida práctica del pago a los oficiales por adelantado, ${ }^{49}$ lo cual constituía un medio empleado para captar mano de obra calificada aunque frecuente motivo de estafas. Una interesante variación se registró en los trabajos contratados por las instituciones religiosas, en donde se otorgaba como parte del pago una tentadora cifra de indulgencias, premiando así el trabajo temporal con un pago espiritual..$^{50}$

Sin embargo, en el contexto de las guerras del siglo XIX, las pobres ganancias que el trabajo artesanal ofrecía a la mayoría de sus integrantes, hacían necesario abrir los horizontes laborales. Entre las prácticas más comunes para aumentar el magro caudal de ingresos, los artesanos solían alquilar las piezas de sus casa-talleres, especialmente a otros artesanos de diversas profesiones. En algunos casos se les permitía residir en calidad de "agregado", aunque tales prácticas fueron sancionadas hacia 1840, por ser consideradas factor que propiciaba la vagancia. ${ }^{51}$

47 AHS, CG 11 núm. 1. Boleta de pago del 17 de septiembre de 1811, al sastre Guzmán, quien recibió 25 pesos por la hechura de 40 varas de yerga con inclusión de hilo y soga de lana de ruedo. El 17 de septiembre de 1811, el maestro herrero Díaz recibió \$48 por la construcción de 16 sables a 3 reales cada uno poniendo el fierro.

48 AHPJ, CG 1832, núm. 2. El maestro platero Rubira recibe la nada despreciable suma de $\$ 8$ por arreglar el reloj público de la iglesia San Francisco. Esta situación se repetía entre sastres y plateros.

AHS, CG 1825 núm. 4. El 1 de febrero de 1825 el sastre Alemán recibió 2 pesos y 6 reales por la compostura de un pantalón, chaqueta y un poncho. Por la hechura de una casaca de uniforme, 3 pares de pantalones y un gorrete de oficial 11 pesos.

49 Tello, Eugenio: Compilación de Leyes y Decretos... Reglamento de multas del 12 de abril de 1851. T.II.

50 Chiericotti, Olga: Historia del Milagro. Salta, 1999. Fuente citada del Archivo del Arzobispado de Salta. Carpeta Iglesia Catedral de Salta. La comisión presidida por el sacerdote don Isidoro Fernández solicitaba: "40 días de indulgencia y remisión a las personas que hagan algún servicio personal, pecuniario o de cualquier otra especie que sea y por cada vez que lo hicieren y a los operarios, jornaleros y demás empleados o artífices, otros tantos por cada día que sirviesen a dicha obra con interés".

51 Tello, Eugenio: Compilación de Leyes y Decretos... Registro Oficial de Jujuy del 16 de mayo de 1840. T.1. 
La inestabilidad del período y la búsqueda de nuevas oportunidades fueron factores que incidieron para debilitar los vínculos corporativos, pues la necesidad de ingresos hacía que el trabajador protagonizara cambios de profesión en su carrera laboral. Así, se encontró a varios individuos ejerciendo distintos oficios que guardaban una cierta relación en cuanto a los conocimientos que éstos implicaban ${ }^{52}$ o bien, empleados en el ejército como parte de las tropas. ${ }^{53}$ Con el transcurrir del tiempo la tendencia a reorientar la mano de obra familiar se acrecentó y algunas familias educaron a sus hijos en oficios distintos a los de sus padres, aunque en general se trataba de profesiones afines; en el mejor de los casos, algún miembro de la familia incursionaba en el comercio minorista, a cargo de una pulpería. ${ }^{54}$

\section{Apuntes sobre fábricas, curtiembres y maestranzas}

Tanto en las ciudades de Salta como de Jujuy se establecieron establecimientos diferentes a los talleres anteriormente descritos, como las fábricas de jabón, las de guardamontes, las curtiembres y las maestranzas. Establecimientos de mayores dimensiones, con más cantidad de empleados y destinados a una producción de carácter relativamente masiva, cuyos mercados trascendieron las fronteras del espacio local. A excepción de las maestranzas, se trataba de establecimientos especializados en la producción de un artículo.

La razón que nos lleva a considerarlos como establecimientos de mayores dimensiones, radica en la forma en que fueron vistos por las autoridades, quienes denominaban fábrica a los establecimientos productores de jabón o de guardamontes y les asignan altos montos de impuestos de patente. ${ }^{55}$ Las manufacturas que alcanzaron importante desarrollo y tecnificación fueron las curtiembres, en Jujuy se contabilizaron tres, siendo la más importante la de la sociedad Tezanos Pinto, Alviña y Cia, con " 4 caleros, 4 lavaderos, 12 cevileros, un motor a vapor, una máquina, para moler

52 AHS, CG 1822/23. Y AHPJ, CG 1834 núm. 1. El maestro Atienza aparece como herrero en 1822 y como armero en 1832 .

53 AHPJ, CG 1823 núm. 123 de diciembre de 1823. El zapatero Herrera fue censado con el grado de capitán. Y el 10 de diciembre de 1823 el zapatero Flores con el grado de sargento.

54 AHS, PN Escribano Arteaga, carpeta 30, protocolo 316, expediente 78. Salta 11 de junio de 1843. En su testamento Acuña le deja a su hijo José Manuel “...una pulpería con la que tiene habilitado a su sobrino Don Pío Graña...”.

55 AHS, CG 22/23. El 24 de agosto de 1822, el maestro Vega cobra 2 pesos por limas para la fábrica de guardamontes. 
cebil, dos grandes galpones para depósito i otro secador a la sombra con reja de fierro"; tos, todos ellos propiedad de importantes comerciantes de la ciudad.

El rendimiento en la producción de estos establecimientos, tanto en la ciudad de Salta como de Jujuy, dio lugar a un interesante circuito comercial, estudiado por Viviana Conti. ${ }^{57}$ Estos establecimientos fueron creciendo en productividad a medida que avanzaba el siglo y hacia fines del XIX aumentaron las cantidades de curtiembres establecidas en la ciudad.

Durante las primeras décadas del siglo XIX, se ubicaron en ambas ciudades las denominadas "Maestranzas del Estado", destinadas a la reparación del armamento de guerra, como cañones o bien a la confección de diversos artículos tales como lanzas, sables, y otros. El personal empleado era predominantemente artesanal, quienes tendieron a desagregar y compartir las tareas, especialmente entre armeros, plateros, herreros, talabarteros y carpinteros ${ }^{58}$ entre todos contaban alrededor de setenta trabajadores calificados. La dirección general estaba a cargo de los maestros plateros o armeros; quienes a su vez se organizaron en maestros mayores y subalternos, los primeros eran responsables del cumplimiento en tiempo y calidad de la producción y los segundos, actuaban como una suerte de capataces. ${ }^{59}$ También se empleaba personal no calificado para tareas más rudimentarias. ${ }^{60}$ Esta tendencia a concentrar mano de obra calificada de profesiones diversas, implantada por el ejército, no tuvo repercusión en la organización del resto de los talleres una vez finalizada la guerra. ${ }^{61}$

En general, el cuerpo de trabajadores orientaba su trabajo de acuerdo con las necesidades que ocasionaba la guerra, aunque la producción generalmente se hacía al por mayor. ${ }^{62}$ Allí los salarios eran relativamente fijos y aparentemente los establecía el ejército. Los pagos se efectuaban por jor-

56 Tello, Eugenio: Compilación de Leyes y Decretos... Registro Oficial del 5 de mayo de 1858.

57 Conti, Viviana: "Espacios económicos y economías regionales: El caso del Norte argentino y su inserción en el área andina en el Siglo XIX", en Revista de Historia. 3, Neuquén, Departamento de Historia. Facultad de Humanidades. Universidad Nacional del Comahue, 1992.

58 AHS, CG 1813 núm. 2, expedientes 19, 34 Y 61. y AHS, CG 1812 núm. 2, expediente 22.

59 Tello, Eugenio: Compilación de Leyes y Decretos... Registro Oficial del 3 de junio de 1859. T. II. Artículo 5 .

60 AHS, CG 1811 núm. 2. Y CG 1813 mes de julio. Relaciones de individuos que trabajaban en las maestranzas de Jujuy.

61 Tales características fueron observadas en los talleres bonaerenses de fines de siglo XIX, por Sábato, Hilda y Romero, Luis Alberto: "Artesanos, oficiales, operarios..."

62 AHS Libro de Hacienda 44. El sastre Garnica recibió 22 pesos, 2 1/2 reales por el corte de 219 chaquetas y 208 pantalones 2 de agosto de 1825 . 
nada $^{63}$ y si ésta se extendía por toda la noche no implicaba un aumento en la remuneración. ${ }^{64}$ Los cuantiosos gastos de guerra contribuyeron a implementar como práctica predominante los pagos en cuotas, ${ }^{65}$ a los que se les descontaba ciertos gastos como los alimentos consumidos durante la jornada laboral ${ }^{66}$ Los criterios de pago variaban de acuerdo al rubro artesanal, siendo los oficios más cotizados los de armeros y plateros, en cambio los talabarteros eran los peor remunerados.

\section{En Sintesis}

Los artesanos urbanos de Salta y Jujuy de la primera mitad del siglo XIX, cumplieron un significativo rol en el abastecimiento de estas ciudades mercantiles y el ejército; a pesar de su escaso peso numérico y económico, especialmente en el caso de los talleres. A excepción de las curtiembres, el sector experimentó escasas transformaciones durante la época analizada, a pesar del desarrollo urbano de ambas ciudades; esto se debió tal vez a las características que asumió en estas regiones la lenta pero implacable expansión de la sociedad de mercado, que privilegiaba los valores individuales por sobre los corporativos.

Dentro de la experiencia cotidiana de los sectores artesanales comenzaron a manifestarse ciertos cambios respecto a las nociones del orden social del antiguo régimen, en el cual las jerarquías se relacionaban más con la sociedad en su conjunto que con los individuos. La pertenencia a las corporaciones definía los privilegios, las obligaciones y los prestigios de los individuos. Con la adopción de las concepciones republicanas, el sentido de identificación a determinados grupos o corporaciones comenzó a depender también de la posesión de algún mérito individual reconocido por

63 AHS, CG 22/23. 21 de septiembre de 1822 Delgado, oficial herrero percibía 3 reales por día, en esa fecha cobra 2 pesos, 2 reales por lo adeudado desde el 16 de noviembre de 1823 . El maestro armero cobraba por semana de trabajo 4 pesos.

AHS, CG 1813 núm. 2, expedientes 19, 34 y 61 y AHS, CG 1812 núm. 2, expediente 22.

64 Ibídem.

65 AHPJ, CG 1832 núm. 2. Al carpintero Díaz se le debe por la construcción de 120 cabos de lanzas y compostura de cajas de fusil 32 pesos, 4r. Se le paga en partes: el 23 de marzo de 1832 recibe 10 pesos; el 24 de marzo de 1832 recibe 20 reales y el 28 de mayo de 1832 recibe 5 pesos.

66 AHS, CG núm. 22/23. El 22 de septiembre de 1822, el maestro platero Fresco cobra por 23 guardamontes y 33 abrazaderos fabricados para los fusiles que compuso, con cargo del descuento del carbón, limas y carne. Son 5 pesos, 7 reales descontados por raciones de carne, componen la cantidad de 9 pesos, 7 reales que importan las hechuras de guardamonte. Se le paga 5 pesos, 7 reales. 
los demás miembros de la sociedad, como la frecuente alusión a los méritos políticos otorgados por los servicios prestados a la causa de la Revolución por algunos maestros herreros en busca de nuevas oportunidades laborales.

En estos rubros, como en gran parte de la sociedad, comenzaron a operar criterios ocupacionales y de riqueza económica en la conformación de las estructuras jerárquicas internas de los sectores sociales, aunque ellas no variaran sustancialmente aún de las tradicionales. De acuerdo a lo estudiado, la cima de las jerarquías artesanales la ostentaban los maestros empleados en los oficios más reconocidos, por debajo se ubicaba el contingente de oficiales y aprendices, y más abajo aún la numerosa población de trabajadores no especializados.

También la movilidad geográfica de la mano de obra actuó como un factor que debilitó los vínculos tradicionales, al reducir la posibilidad de experiencias compartidas y la conciencia comunitaria que eran las bases de la tradición corporativa; sin embargo, los artesanos intentaron estrategias para mantenerlas, como el traslado de todos los integrantes de las compañias artesanales o la convivencia entre maestros y ayudantes en los talleres. Así, el sistema corporativo sobre el que organizaron sus actividades, les permitió conservar ciertas características culturales de carácter tradicional, como las formas de operar y de transmitir las habilidades propias de cada oficio, lo cual les permitió distinguirse del resto del conglomerado social urbano. Si bien estos grupos representaron la mano de obra pobre de las ciudades estudiadas, les permitieron desempeñar su papel de ciudades mercantiles al participar en los escenarios vitales del intercambio social y económico. 
MAPA N. ${ }^{\circ} 1$

LAS CIUDADES DE SALTA Y JUJUY EN LOS ALBORES DEL SIGLO XIX

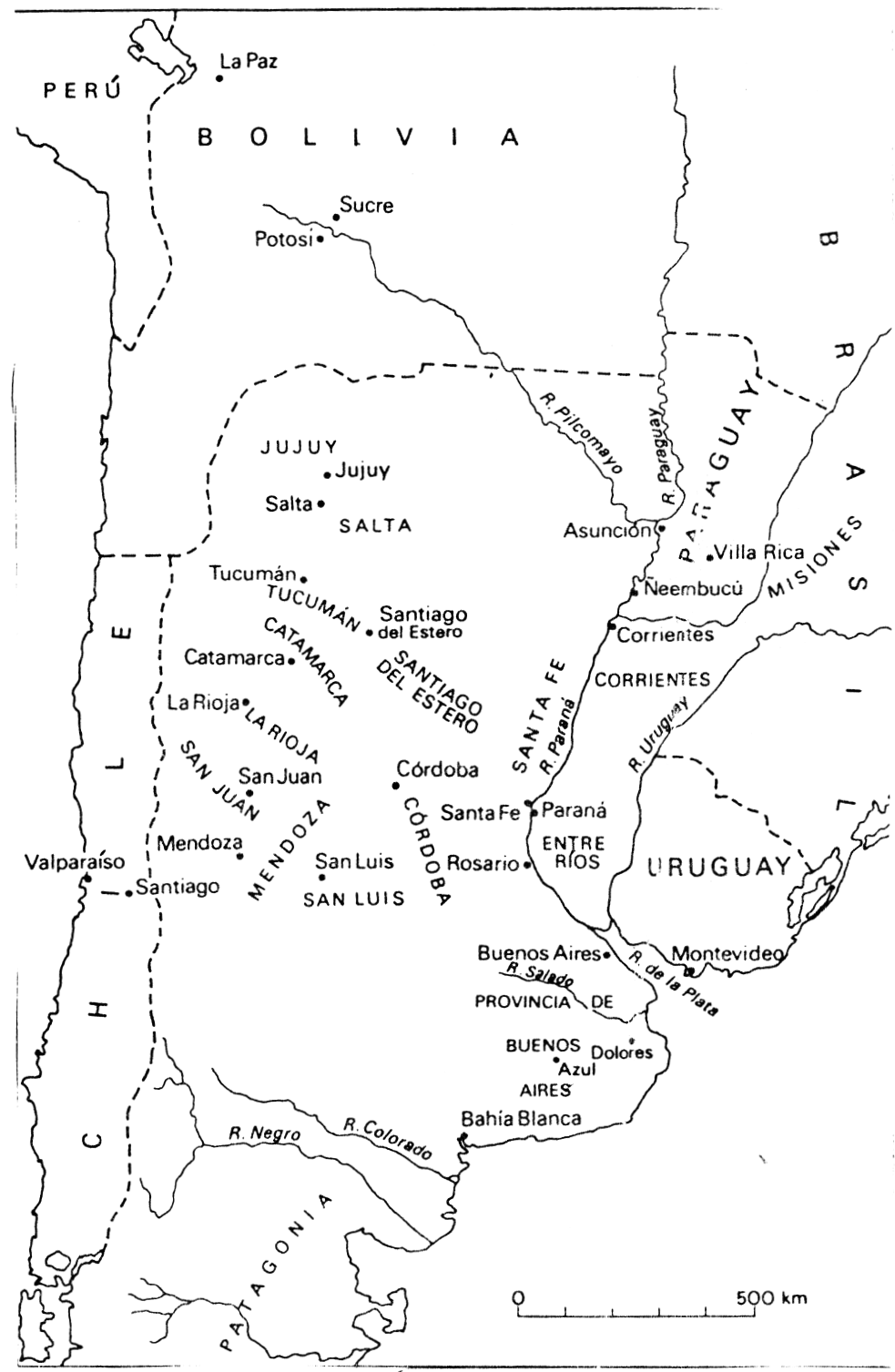


EMMA TERESITA RASPI

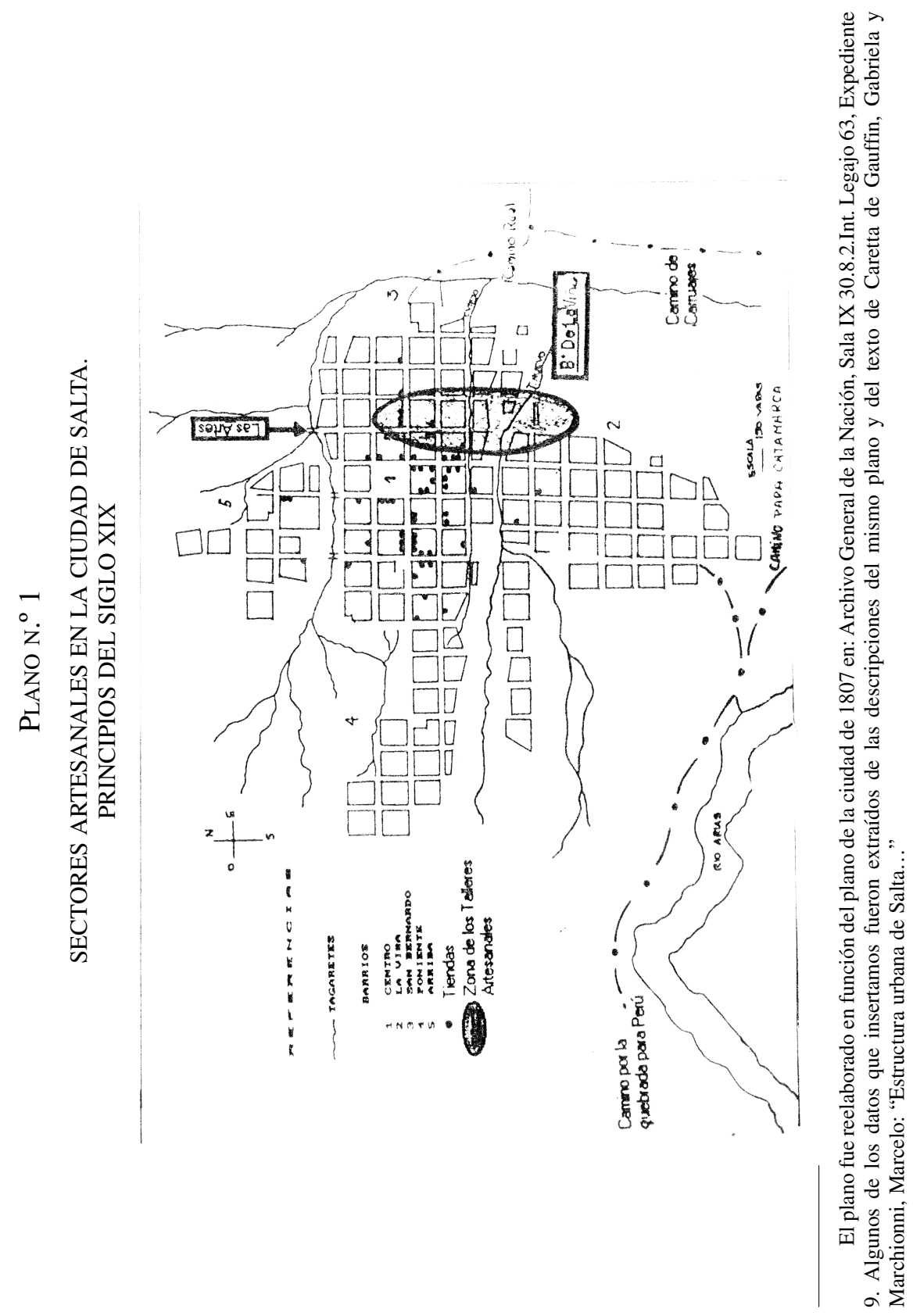




\section{PLANO N. ${ }^{\circ} 2$}

SECTORES ARTESANALES EN SAN SALVADOR DE JUJUY. PRINCIPIOS DEL SIGLO XIX

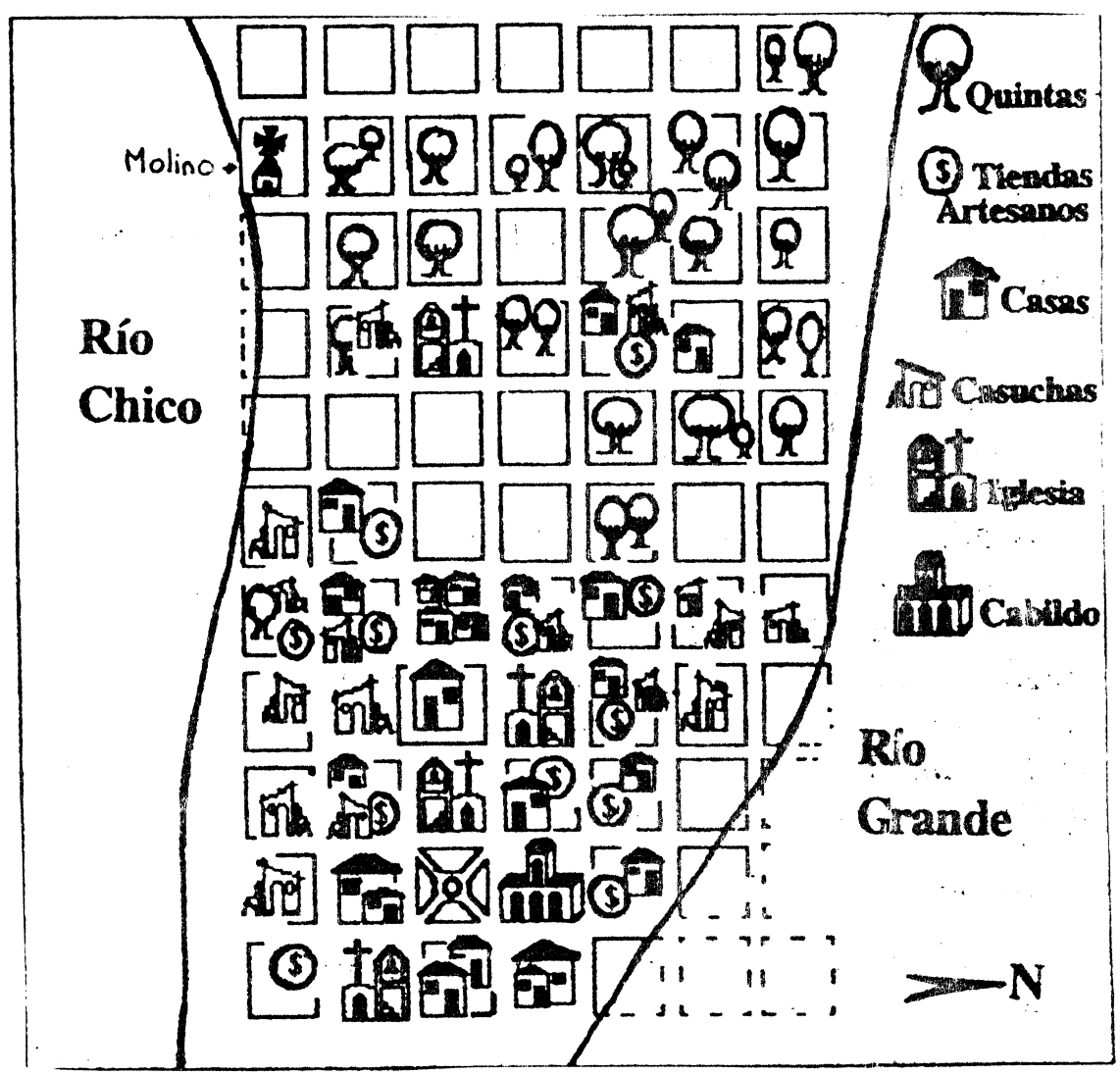

Los talleres indicados son los que logramos ubicar espacialmente hasta el momento. La ubicación de las casas se realizó por cuadras, y es relativamente imprecisa. El plano fue confeccionado a partir del efectuado por Raque1 Gil Montero, "La ciudad de Jujuy y su campaña circundante: Algunos aspectos de su población entre fines del Siglo XVIII y mediados del Siglo XIX". En: Jujuy en la Historia. T. II. UNHIR Universidad Nacional de Jujuy. 